Published in final edited form as:

Adv Drug Deliv Rev. 2012 August ; 64(11): 1021-1030. doi:10.1016/j.addr.2012.01.003.

\title{
Engineering nanomedicines using stimuli-responsive biomaterials
}

\author{
Yapei Wanga ${ }^{a}$, James D. Byrne ${ }^{a}$, Mary E. Napiera, and Joseph M. DeSimone ${ }^{a, b, c, d, e, f, g, h,{ }^{*}}$ \\ aDepartment of Chemistry, University of North Carolina at Chapel Hill, Chapel Hill, North Carolina \\ 27599, USA \\ bDepartment of Pharmacology, University of North Carolina at Chapel Hill, Chapel Hill, North \\ Carolina 27599, USA \\ CLineberger Comprehensive Cancer Center, University of North Carolina at Chapel Hill, Chapel \\ Hill, North Carolina 27599, USA \\ dInstitute for Nanomedicine, University of North Carolina at Chapel Hill, Chapel Hill, North \\ Carolina 27599, USA \\ eEschelman School of Pharmacy, University of North Carolina at Chapel Hill, Chapel Hill, North \\ Carolina 27599, USA \\ 'Institute for Advanced Materials, University of North Carolina at Chapel Hill, Chapel Hill, North \\ Carolina 27599, USA \\ gDepartment of Chemical Engineering, North Carolina State University, Raleigh, North Carolina \\ 27695, USA \\ hSloan-Kettering Institute for Cancer Research, Memorial Sloan-Kettering Cancer Center, New \\ York, NY 10065, USA
}

\section{Abstract}

The ability to engineer particles has the potential to shift the paradigm in the creation of new medicines and diagnostics. Complete control over particle characteristics, such as size, shape, mechanical property, and surface chemistry, can enable rapid translation and facilitate the US Food and Drug Administration (FDA) approval of particle technologies for the treatment of cancer, infectious diseases, diabetes, and a host of other major illnesses. The incorporation of natural and artificial external stimuli to trigger the release of drugs enables exquisite control over the release profiles of drugs in a given environment. In this article, we examine several readily scalable top-down methods for the fabrication of shape-specific particles that utilize stimuliresponsive biomaterials for controlled drug delivery. Special attention is given to Particle Replication In Nonwetting Templates (PRINT ${ }^{\circledR}$ ) technology and the application of novel triggered-release synthetic and natural polymers.

(C) 2011 Elsevier B.V. All rights reserved.

desimone@unc.edu.

Publisher's Disclaimer: This is a PDF file of an unedited manuscript that has been accepted for publication. As a service to our customers we are providing this early version of the manuscript. The manuscript will undergo copyediting, typesetting, and review of the resulting proof before it is published in its final citable form. Please note that during the production process errors may be discovered which could affect the content, and all legal disclaimers that apply to the journal pertain. 


\section{Keywords}

Top-down; Trigger-release; Microfluidic; Photolithography; PRINT

\section{Introduction}

The ability to engineer particles allows for precise control over the delivery of drugs and diagnostic agents. Over the past two decades, significant progress has been made in the development of particle systems that are capable of overcoming many biological barriers (ie. PEGylated particles bypassing the reticuloendothelial system and intra-nuclear delivery of drugs using nuclear localization signal peptide sequences) [1-3]. An important aspect of particle-based medicines is the ability to deliver cargo to a site of interest. Stimuliresponsive biomaterials enable effective site-specific delivery of drugs by exploiting physiologic conditions in vivo. In this review, we examine natural stimuli-responsive biomaterials for controlled drug delivery and several scalable top-down methods for fabricating particles of the stimuli-responsive biomaterials.

\subsection{Engineering Particle Systems: Top-Down versus Bottom-Up Fabrication Methods}

The two major classes of particle fabrication are top-down and bottom-up methods. Bottomup particle fabrication methods build the particle from the atomic or molecular level with the desired particle physical parameters, whereas top-down particle fabrication methods process a material beginning at the macroscopic level to the desired size and shape scale. Medicines made by bottom-up fabrication methods have received much attention for being the primary drug delivery systems at the forefront of nanotechnology [4-7]. Bottom-up methods rely upon the self-assembly of molecules for creation of particles such as micelles, vesicles, liposomes, and polymersomes where drugs and diagnostic agents are encapsulated in the interior of the particle [8]. The self-assembly process is readily scalable but lacks the fine control over size, shape, and degradation.

Top down fabrication techniques allow for the simultaneous control over chemical composition, particle size, shape, cargo, mechanical property, and surface chemistries (antibodies, PEG chains, metal chelators) that can precisely realize intracellular delivery for bioactivity. Lithography has expanded the top-down particle fabrication platform through the development of patterned surfaces [9]. Photolithography, electron beam lithography, and ion beam lithography allows for highly scalable patterned surfaces with smaller and smaller feature sizes [10]. The generated patterned surfaces enable the techniques of molding, embossing, and transfer printing [11]. These techniques are at the forefront of devising new strategies to systematically engineer particles using stimuli-responsive biomaterials. Currently, the emerging top-down strategies capable of controlling size and shape are microfluidics, photolithographic methods, and imprint lithographic methods.

\subsection{Important Factors in Particle Design}

Long circulation times, reduction in secondary effects of drugs, accumulation in organs of interest, biocompatibility, and controlled degradation are all factors of drug vehicles that play important roles in the therapeutic efficacy. In this regard, particle design is a critical determinant of the therapeutic efficacy of particle-based medicines. Both chemical and physical properties of particles have been recognized as critical in the success of drug delivery in vivo [12]. Surface chemistry has shown to reduce protein adsorption and phagocytosis [13-17], or direct the particles to the target tissues [18, 19]. In the physical aspect, the size plays a role in particle biodistribution. The particles less than $5 \mathrm{~nm}$ are cleared rapidly from the circulation by extravasation or renal clearance [20, 21]. Spherical 
particles with the size range from $10 \mathrm{~nm}$ to $15 \mu \mathrm{m}$ have been studied widely in terms of biodistribution [22-24]. There have been several experimental examples of the impact of size and shape on particle internalization and biodistribution. [25] Long cylindrical filaments achieved via self-assembly of block copolymer into worm-like micelles, displayed negligible phagocytosis compared with spheres of a similar volume [26]. In a separate study, the investigation of spherical and elliptical disk-shape polystyrene microparticles during phagocytosis by alveolar macrophages indicated that macrophages internalized particles along the major axis while particles were not internalized along the minor axis after 12 hours [27]. Red blood cell mimics $(\sim 6 \mu \mathrm{m})$ have shown that the micrometer-sized deformable particles can bypass several organs. These red blood cell mimics were used to mimic the mechanical properties of red blood cell, showing an 8-fold decrease in Young's modulus correlated to a greater than 3-fold increase in the elimination half-life [28]. Additionally, particle matrix also plays an important role in drug delivery. Stimuli-responsive biomaterials and natural polymers enable exquisite control over the release of drug at the site of action.

\section{Stimuli-Responsive Biomaterials used in Engineered Particle Systems}

Considerable effort has been devoted to controlling the release of cargo and the degradation of the particle. Particles made up of stimuli-responsive materials have been developed to release their encapsulated cargo in extracellular and intracellular compartments. This control of drug delivery enables more specificity in drug accumulation and reduced non-specific toxicity. Triggered release of the drug is made possible through artificial stimuli [29], such as light-irradiation, magnetic, ultrasonic, thermal, and electric, as well as natural stimuli, such as pH changes [30], redox gradients [31], and enzymatic stimuli [32]. Natural stimuli within pathways of cellular uptake or tissue environments are emerging as major triggers for designing engineered particles, since they happen spontaneously in vivo, avoiding the use of any extra assistance. In general, the characteristics of a clinically relevant particle matrix should be i) non-toxic, ii) capable of maintaining good mechanical integrity until degradation, and iii) controlled degradation profile. In addition, the degradation byproducts should be also non-toxic and cleared by the body. In regard to these aspects, biodegradable polymers and hydrogels with cleavable linkers that respond to natural stimuli have gained tremendous research interest in the area of biodegradable particle fabrication. Practical examples of biomaterials responding to natural $\mathrm{pH}$ gradients, redox gradients, and enzymatic catalysis are discussed in more detail below.

\section{1 pH Gradients}

Certain tumors and inflamed tissue have a slightly lower $\mathrm{pH}$ values (between $\mathrm{pH} 5.4$ and 7.4) than homeostatic conditions (pH 7.4) [33, 34]. Furthermore, there exists a lower intracellular $\mathrm{pH}$ in endosomes and lysosomes. As such, particles internalized through endocytosis will experience a $\mathrm{pH}$ gradient from neutral $(\mathrm{pH} \sim 7.4)$ in extracellular environment, to acidic $(\mathrm{pH} \sim 6.2)$ in early endosome and more acidic $(\mathrm{pH} 5.0)$ in lysosome. [35]. Acid-cleavable biomaterials have been used to generate engineered particles to be degraded by the $\mathrm{pH}$ change from extracellular compartment to the intracellular endosome. Specifically, the linkers having acidic labile groups such as hydrazones, trityls, aconityls, vinyl ethers, polyketals, acetals, poly(orthoesters), thiopropionates, and silyl ethers [36-44].

\subsection{Redox Gradients}

In eukaryotic cells, disulfide bonds between cysteines within proteins are formed in the endoplasmic reticulum (ER) to fortify the protein tertiary structure [31]. The lumen of the ER has an oxidizing environment, as the glutathione (GSH):glutathione disulfide (GSSG) ratio is estimated to be 1:3. The redox state of GSH in cytosol is biased to a greatly reduced state as a result of a ratio of GSH to GSSG, which is greater than 100 in most cells. This 
ratio is maintained by the catalytic conversion of GSSG to GSH by glutathione reductase and NADPH [45]. In contrast to 1-10 $\mathrm{mM}$ glutathione in the cytosol, glutathione (GSH) concentration in the extracellular environment is much lower, typically $\sim 10 \mu \mathrm{M}$ in plasma [46]. Thus, there is a redox gradient existing between extracellular environment and the reducing intracellular space. Reductively labile linkers containing disulfide bonds can be used for degradation upon cellular internalization, since the reduction of disulfide bond is initiated by the redox gradient in the pathways of endosome and lysosome [47].

\subsection{Enzymatic Stimuli}

Almost all cellular processes require the assistance of enzymes. Substrate specificity enables enzymes to be highly selective. Materials that can be digested by specific enzymes are regarded as promising candidates for fabricating drug carriers. Three major examples of enzyme-triggered release of drugs are the controlled release of insulin by glucose oxidase through an acid-labile linker [48-50], dextran particles degraded by dextranase [51], and protein based particles digested by protease $[52,53]$. The pathogenesis of diabetes (type 1 and type 2) involves the inability of the pancreas to control blood glucose concentration by the reduced secretion of insulin [54]. Glucose oxidase triggers the conversion of glucose to gluconic acid, thus increasing the local proton concentration, which allows for a platform of controlled release of insulin from the $\mathrm{pH}$-sensitive systems [48-50]. As an example of microbial enzymes, dextranase is always present in the colon, triggering the degradation of polysaccharide dextran. As such, the dextran-based particles break apart, inducing a release of encapsulated drugs into human colons [51]. Protease, a proteolytic enzyme, begins protein catabolism by hydrolysis of the peptide bonds in the polypeptide chain. Proteases are currently classified into six broad groups, including serine proteases, threonine proteases, cysteine proteases, aspartate proteases, metalloproteases, and glutamic acid proteases [52, 53]. These different proteases differ in substrate specificity. Tailored by the proteolytic hydrolysis in the presence of specific protease, proteins can be degraded into nontoxic short peptides or amino acids. At this point, proteins are being widely evaluated as an essential family of biopharmaceutical substances for creating new drug vehicles.

\section{Methods for Engineering Stimuli-Responsive Particles}

There are many different top-down methods for fabricating particles with a variety of physical and chemical characteristics. We have highlighted a number of top-down methods that can be used to fabricate particles made up of stimuli-responsive materials, as summarized in Table 1.

\subsection{Microfluidic Particle fabrication}

Particle fabrication using microfluidic channels is an emerging strategy for the creation of particles with control over size and shape. The microfluidic channel is routinely replicated using polydimethylsiloxane (PDMS) or polyurethane (PU) from a patterned surface prepared by SU-8 photoresist on silicon wafers. The minimum feature size is determined by the lithographic method. Two microfluidic apparatuses, T-junction microchannel (Fig. 1A-a) $[55,56]$ and the planar flow-focusing device (FFD) (Fig. 1A-b) [57] are broadly implemented in particle fabrication [58-61]. In principle, shear forces exerted by a flowing continuous phase creates a micrometer-sized monodisperse emulsion droplet. The emulsion drop size in the continuous phase is determined by a dimensionless parameter $\mathrm{Q}_{\mathrm{d}} / \mathrm{Q}_{\mathrm{c}}$ and the capillary number $C_{a}$ where $Q_{d}$ and $Q_{c}$ are the flow rates of dispersed phase and continuous phase, respectively, and $\mathrm{C}_{\mathrm{a}}$ is the ratio of shear force exerted by the continuous phase to the surface force at the interface of the emulsion drops [56]. In addition, drops of dispersed phased in T-junctions can be separated by a shear force created by the flow of continuous phase. The size $(10 \mu \mathrm{m} \sim 200 \mu \mathrm{m})$ and shape (sphere or elongated) can be well tuned by the 
channel width and flow rates. In the FFD device, a coaxially flowing continuous phase fluid flanks the dispersed phase on both sides, breaking off the droplet immediately after a narrow orifice [57]. Not only spheres and ellipsoids but also cylinders and discs can be generated by FFD. The shape of the particle is dependent on the narrow orifice where the dispersed phase is broken up [62]. There are several approaches to solidify the emulsion droplets and form robust particles, such as cooling the droplets below their melting point, evaporating the solvents from the solid polymers, photo-curing or thermal polymerization of the emulsion droplets containing reactive reagents.

In addition, a new type of flow lithography approach, continuous-flow lithography (CFL) (Fig. 1B), was reported to produce particles with more complex shapes in microfluidic devices [63]. A photomask with a unique shape is covered on a microfluidic channel, allowing a flowing stream of photocurable monomers to be selectively exposed to the UV light. The monomers in the UV-exposure region are crosslinked into solid particles. The surface polymerization of the particles is inhibited by flowing oxygen along the inner wall of the microfluidic channel, inducing an uncrosslinked layer which enables the particles to flow out of the channels without sticking to the channel wall. Photomasks can be chosen expanding the particle shapes from the spheres generated by droplet-based method to several others, e. g. triangles, circles, squares, rings, etc. However, particle size is limited by the CFL method because of blurring and smearing of the particles. This is overcome by stopflow lithography (SFL), a process during which the flow of monomer is temporarily stopped during each photo-curing step [64]. Because of the nature of this fabrication method, there are some limitations to this technique: i) formulations of the particles, ii) size of the particle, and iii) solvents of the dispersed phase without swelling the microfluidic channel. A variety of photocurable crosslinkers consisting of $\mathrm{pH}$-cleavable, reductively labile, enzymeresponsive, or antigen-sensitive moieties have been designed and studied in many traditional hydrogel systems $[31,32,34,65,66]$. In the area of drug delivery, there is significant potential for the microfluidic fabrication of particles made with stimuli-responsive materials.

Biodegradable polymers such as poly(lactic acid-glycolic acid) (PLGA) have been broadly used as matrices for drug delivery [67, 68]. PLGA has been successful as a biodegradable polymer because it undergoes hydrolysis in the body to produce the original monomers, lactic acid and glycolic acid. These two monomers are by-products of various metabolic pathways in the body. There is very minimal systemic toxicity associated with PLGA for drug delivery or biomaterial applications. PLGA degrades by hydrolysis of its ester linkages in the presence of water, which can shift the local $\mathrm{pH}$ when PLGA is given in large quantities. [69] It has been shown that the time required for degradation of PLGA is related to the monomers' ratio used in production: the higher the content of glycolide units, the longer the degradation time. An exception to this rule is the copolymer with a 50:50 monomer ratio that exhibits faster degradation [70].

Anderson et al. demonstrated the fabrication of monodisperse, drug-encapsulated PLGA microparticles using the microfluidic flow-focusing device (FFD) [71]. The dispersed phase was composed of PLGA, drug (bupivacaine), and dichloromethane while an aqueous solution containing $1 \%$ poly(vinyl alcohol) (PVA) was utilized as a continuous phase. The emulsion droplets were collected in a buffer solution ( $\mathrm{pH} \mathrm{8.5)} \mathrm{that} \mathrm{minimized} \mathrm{the} \mathrm{particle}$ aggregation and leaching of bupivacaine. Solid PLGA particles encapsulating drugs resulted after evaporating organic solvent, and the particle size was well-tuned by adjusting the flowing rates of the two phases. Drug release studies indicated that smaller particles released cargos faster than the bigger particles, which was due to the larger surface area-to-volume ratio of the smaller particles. In comparison to the particles produced by conventional emulsion methods with the similar average size, the microfluidic particles released drugs relatively slower. In addition, the initial burst release of drug from monodisperse 
microfluidic particles was significantly reduced than that observed from corresponding polydisperse conventional solvent emulsification particles, as shown in Fig. 2. The difference in drug release between the two kinds of particles was attributed to a difference in drug entrapment in the particles. Less drug was adsorbed or trapped close to the surface of microfluidic particles, suggesting that microfluidic fabrication can homogenously mix all the components in the dispersed phase leading to the particle fabrication with uniform drug distribution.

Nanometer sized particles can be created by using a diblock polymer of poly(lactic acidglycolide)-b-poly(ethylene glycol) (PEG-PLGA) in a microfluidic device [72]. PEG-PLGA dissolved in acetonitrile was directed through a microfludic channel, rapidly mixing with another flowing water phase. The nanoprecipitation of hydrophobic PLGA segments was induced by the solvent diffusion, resulting in formation of self-assembled particles in microfluidic devices. Rapid solvent mixing by hydrodynamic flow focusing can overcome the size limitation existing in conventional self-assembly processes. This is because the solvent diffusion can be tuned faster than the polymer chain aggregation via increased flowing rates, leading to smaller sized particles. The PEG-PLGA particle in this example had an average size around $30 \mathrm{~nm}$, which is much smaller than that (over $100 \mathrm{~nm}$ ) produced by well-known bulk methods. Although the co-precipitation with PLGA polymer increased the size of the particle, hydrodynamic flow focusing prevented nanoparticle aggregation resulting in smaller and more homogeneous nanoparticles. In contrast, the addition of PLGA in the PEG-PLGA decreased the barrier nanoparticle/polymer aggregation and favored the formation of larger polydisperse nanoparticles in bulk synthesis. Further studies indicated that the incorporation of PLGA in the particle can enhance the drug loading and encapsulation efficiency while decreasing the drug release rate. However, rather than traditional emulsion methods, the synthesis of nanoparticles by self-assembly of block copolymer precursors in microfluidic devices could enable better control over the nanoparticle size, homogeneity, and drug loading and release.

Moreover, the self-assembly of biodegradable block copolymers in the microfluidic channels can also generate polymersomes, having a similar bilayer structure to vesicles [73]. A triphase emulsion droplet, $\mathrm{W} / \mathrm{O} / \mathrm{W}$, was formed in the dripping regime from a small injection tube in a co-flow geometry with the middle oil stream containing the inner drops being flow-focused by the outer continuous phase, breaking up into double emulsion drops. Amphiphilic diblock copolymer poly(ethylene glycol)-b-poly(lactic acid) dispersed in the oil phase consisting of toluene and chloroform moved to the W/O interface to stabilize the emulsion droplet. After the evaporation of the organic solvent, monodisperse polymersomes were obtained, which could be designed as carriers for the encapsulation of hydrophilic cargos.

Lastly, microgels with a network structure are attracting considerable attention as smart matrices in drug delivery. Microfluidic methods have become effective techniques for fabricating monodisperse microgel particles, composed of agarose, alginate, or photocurable organic prepolymers [74-78]. Photopolymerized microfluidic microgel particles can be prepared using two different processes. One method is direct photopolymerization of emulsion droplets containing photocurable prepolymers in either T-junction or FFD devices. Another method is selective photopolymerization of prepolymer solution in CFL or SFL devices, generating more complex structures than the former method. An introduction of labile linkages within a prepolymer can be applied to trigger the release of drug and degradation of the microgel for controlled drug delivery. One example was the photopolymerization of emulsion droplets containing dextran-hydroxyethyl methacrylate (dex-HEAMA) in FFD microfluidic device [79]. The resulting particles with an average size of $9.9 \mu \mathrm{m}$ exhibited much better uniformity than those prepared by conventional emulsion 
method. The hydrolysis of carbonate ester groups within the microgel network led to the separated dextran chains and polymerized methacrylate groups, resulting in the gradual particle degradation. In another example, a biodegradable polymer, poly(lactic acid), was used as a labile linkage in a photocurable prepolymer, diacrylate PLA-b-PEG-b-PLA [80]. The shape-specific microgel particles were fabricated in SFL devices with a desired pulse of UV exposure through a photomask. PLA degradation was found to induce cargo release and a drop in the Young's modulus of the microgel particles.

\subsection{Photolithographic Methods}

Photolithography has been exploited for the fabrication of discrete monodisperse particles [65, 81-83]. The basic principle of photolithography for generating particles is similar to the fabrication of patterned surfaces. In the particle fabrication process, as seen in Fig. 3a substrate is coated with a sacrificial layer and subsequently with a layer of photocurable prepolymer. The prepolymer layer is allowed to be selectively exposed to UV light through a mask with shape- and size-specific features. As the prepolymer exposed to UV light is photopolymerized, the uncured prepolymer and the sacrificial layer are both washed away, resulting in the free particles. Some early monodisperse lithographical particles generated from photoresist have been broadly exploited for the directed colloidal self-assembly [84]. However, photoresist-based particles are limited in their toxicity and poor degradation for drug delivery. Emerging photocurable prepolymers such as PEG-based crosslinkers enable the fabrication of biocompatible microgel particles by photolithography technique [85-87]. The advantage of photolithography particle fabrication is excellent shape fidelity down to the submicrometer level, and the process can be high-throughput. Nearly all studies to date involve robust crosslinked PEG microgels that exhibit negligible cytotoxicity and no degradation. The introduction of labile linkages onto the prepolymer as addressed in microfluidic method could become a strategy for the synthesis of biodegradable lithography particles.

\subsection{Particle Replication in Non-wetting Templates (PRINT®) and other micromolding methods}

The method involving soft-lithography-based micromolding with lift-off strategy pioneered by Whitesides et al., has also been developed to fabricate engineered particles with control over size and shape [88]. This method takes advantage of a template master generated by photolithography for desired feature size and shape. An elastomeric mold is replicated from this rigid master, creating an array of cavitary structures. Micromolding was early envisioned as a low-cost tool using a PDMS stamp for micro and nanoscale pattern replication rather than the fabrication of distinct particles. This is due to the challenge of removing the residual layer (flash layer) that connects the particles. A micromolding technique called PRINT (Particle Replication in Non-wetting Templates) utilizing a fluorinated elastomeric mold was developed by DeSimone and colleagues in 2005, as the first micromolding example for the scalable fabrication of distinct particles without the formation of a flash layer [89].

In PRINT process, the synthesis of a photocurable, perfluoropolyether (PFPE)-based elastomer (Fluorocur ${ }^{\mathrm{TM}}$ ), enabled the molding of patterned surfaces with improved masterto-template fidelity and reproducibility at smaller feature sizes compared to silicone-based elastomers [90, 91]. As shown in Fig. 4, the durable perfluoropolyether (PFPE) molds with size- and shape-specific cavities are replicated from a master template [92, 93]. To create the PFPE molds, liquid PFPE resin is drop cast on a silicon master and further cured onto a backing poly(ethylene terephthalate) (PET) film. The PFPE mold can be used in a roll-toroll system for large scale production of particles [94]. As PFPE molds exhibit non-wetting behavior and excellent compatibility to most liquid materials, the cavities are easily filled by 
liquid particle matrices, including solutions of organic solvents, monomers, polymers, aqueous protein solutions, and biologics. Once the liquid particle precursor fills the cavities and are solidified, the array of particles can be removed from the mold and collected.

The PRINT process enables large scale fabrication of precisely defined nanoparticles with control over particle size ( $20 \mathrm{~nm}$ to 100 micron) and shape based on the master template [95]. The PRINT process enables the mapping of important variables in nanomedicine, such as the interdependency of the physical parameters of the particles - size, shape, mechanical property, chemical composition and surface chemistry - on biodistribution, bioavailability, and therapeutic efficacy for medical applications [25, 28, 44]. Monodisperse PRINT particles have been loaded with a variety of cargos, including therapeutics, oligonucleotides, vaccines, proteins, siRNA, and imaging agents [96]. Triggered release of this cargo has been an active area of research in our lab, as we have explored a variety of stimuli-responsive biomaterials.

PLGA PRINT particles have been successfully fabricated in a wide variety of size and shape [97]. In the typical PRINT process, filling PLGA polymers into the mold cavities requires a phase transition step. A film of PLGA polymer is cast to a desired thickness and is briefly heated upon contact with a mold, allowing the polymer to flow into the wells by capillary force. As the polymer is cooled below its phase transition temperature, the particles solidify. The particles can then be transferred from the mold to a sacrificial layer (polyvinyl alcohol) by briefly reheating when in contact with a harvesting surface. The particles can then be collected by separating particles from the sacrificial harvesting layer. Several shapes have been fabricated, as shown in Fig.5.

The PRINT process has exhibited enhanced drug loading with higher encapsulation efficiency when compared to traditional solvent emulsification methods. In $200 \times 200 \mathrm{~nm}$ cylindrical PLGA particles, the concentration of loaded docetaxel ranges from $0 \%$ to $40 \%$ with an encapsulation efficiency over $90 \%$. Differential scanning calorimetry study demonstrated that the drug was not crosslinked to the polymer and had not undergone fusion or crystallization. Blank PLGA particles without drug were nontoxic to SKOV3 (ovarian carcinoma) cells. However, docetaxel-loaded PLGA 200x200nm particles exhibited dosedependent cytotoxicity and were toxic in sub-nanomolar docetaxel concentrations. These results demonstrated that the PRINT process allows for high encapsulation of docetaxel but also high cytotoxicity when delivering docetaxel.

PRINT particles containing disulfide cross-linker have been fabricated to release a chemotherapy agent and degrade in a reducing environment. These stimuli-responsive particles were generated from the co-polymerization of several liquid monomers in the mold under UV irradiation [98]. A prepolymer solution consisting of a disulfide cross-linker (Fig 6), an inert cross-linker, aminoethylmethacrylate, photoinitiator, and cargo (Doxorubicin) was filled in mold cavity and photopolymerized. The particles containing $30 \mathrm{wt} \%$ disulfide crosslinker were stable in phosphate buffered saline (PBS) solution, but the particles released doxorubicin upon the addition of a reductive agent of $100 \mathrm{mM}$ dithiothreitol (DTT). The control particle without the disulfide crosslinker was stable in a $100 \mathrm{mM}$ DTT PBS solution. The control particles were extremely biocompatible, with cell viability at the highest dosing of blank PRINT particles $(0.64 \mathrm{mg} / \mathrm{mL})$ showing no cytotoxicity. PRINT particles dosing $2 \mathrm{wt}$ \% \% Doxorubicin with $30 \mathrm{wt} \%$ disulfide cross-linker were efficient at killing HeLa cells with more than $50 \%$ of the cells killed at a dosing of $160 \mu \mathrm{g} / \mathrm{mL}$ PRINT particles, while PRINT particles dosing 2 wt. \% Doxorubicin without the reductively labile crosslinker showed no cellular toxicity. 
A group of novel $\mathrm{pH}$-sensitive crosslinkers were fabricated for release of drugs in tumor environment and an endosomal compartment. The $\mathrm{pH}$-sensitive crosslinkers were bifunctional silyl ether crosslinkers prepared with a variety of substituents on the silicon atom; the collection included dimethylsilyl (DMS), diethylsilyl (DES), diisopropylsilyl (DIS), and di-tert-butylsilyl (DTS) ether crosslinkers (Fig. 7A) [44]. The silyl ether-based crosslinkers were photopolymerized with PEG diacrylate to create PRINT microparticles. Two particle shapes were fabricated $-5 \mu \mathrm{m}$ cube particles and $3 \mu \mathrm{m}$ hexnut particles. The release kinetics of a dye from the cubic particles were analyzed at two different $\mathrm{pH}$ values. Rhodamine-B release as a function of time was evaluated for the particles fabricated with the DMS crosslinker, which displayed an accelerated rate of degradation when dispersed in a medium buffered at $\mathrm{pH} 5.0$ and exhibited a degradation half-life of 0.091 days (2.19 hours). The same particles dispersed in a medium buffered at $\mathrm{pH} 6.0$ had a half-life of 1.08 days, and particles dispersed in a medium buffered at $\mathrm{pH} 7.4$ had a half-life of 2.94 days.

Intracellular degradation of the silyl ether PRINT particles was evaluated using TEM (Figure 7B). Hexnut shaped particles were chosen for the studies because the unique shape was easily distinguishable from other intracellular components. Two batches of particles were evaluated, particles made with the rapidly degrading crosslinker (DMS) and particles made with the non-degrading crosslinker (DTS). A positively charged component was added to the particle matrix ( $\mathrm{N}$-(3-aminopropyl)methacrylamide hydrochloride) to ensure cellular internalization by HeLa cells. As a function of the TEM bright-field mode, low-density material appeared white and high-density material appeared dark. Figure 7B-a shows one internalized DMS particle and three DMS particles outside of the cell. The internalized particle (Figure 7B-b) appeared less dense than the particles outside of the cell (Figure 7Bc). The DMS particles appeared to undergo a change in density by swelling (Figure 7B-d), fragmenting (Figure 7B-e), and undergoing surface erosion (Figure 7B-f). DTS particles were also internalized and exposed to the acidic environment of the endosome and lysosome; however, there was no noticeable change in the size, shape, and density of the DTS particles. The particles were not susceptible to degradation because of the stability of the DTS crosslinkers.

Furthermore, protein particles were fabricated for the encapsulation and delivery of macromolecular biological cargos. The degradation products of proteins or proteins themselves are biocompatible and nontoxic. Insulin, albumin, and albumin mixtures with siRNA or paclitaxel were molded into shape-specific particles on the basis of PRINT technique. Molding these protein complex was performed by a lamination technique where an aqueous protein solution ( $25 \mathrm{wt} \%$ ) was placed between PFPE mold and another cover film. An applied pressure can remove the excess protein solution, leaving a filled PFPE mold without the formation of flash layer on top. Solid protein particles were lyophilized in the mold and free particles were harvested from a sacrificial layer. Particles with control over size and shape, $2 \mu \mathrm{m}, 5 \mu \mathrm{m}, 200 \mathrm{~nm}$ cubes and cylinders were successfully generated. Overall, the PRINT technology offers a facile, rapid, and gentle fabrication process for shape-specific, monodisperse protein particles using any protein [99]. There are ongoing efforts to investigate numerous other proteins, including hormones, antibodies, and enzymes. Recently, micromolding methods using other elastomeric molds (e.g. PDMS, hydrogel) have also been emerged to create engineered particles with control over size and shape, although a careful process is required for the removal of the flash layer on the particles.

Rather than regular photolithography method, these additional micromolding methods are also able to broadly mold biodegradable polymers, photocurable prepolymers, or gelators, leading to the creation of biodegradable engineered particles. However, an examination of solvent and particle precursor is necessary to demonstrate if the mold can be compatible 
with them. The particle fabrication process is similar to PRINT, beginning with mold filling with a particle precursor followed by subsequent particle solidification, and finishing with particle isolation. [100-102]. For example, thermoplastic PLGA particles with highly uniform size and a plate-like morphology were produced by micromolding method using PDMS mold [103, 104]. Specifically, the microwells on PDMS mold were filled by dipping the mold in a PLGA acetone solution and followed by evaporation of the solvent. At $3 \mathrm{wt} \%$, a PLGA film covered the whole PDMS stamp. PLGA on the surface of protruding microfeatures were transferred onto a substrate before the PLGA particles in the mold cavities were isolated onto a poly(vinyl alcohol) layer. Free particles were eventually separated from the poly(vinyl alcohol) by dissolution of the poly(vinyl alcohol). In addition, a gelatin-based mold has also been used, which can resist particular organic solvents such as methylene chloride that is a good solvent to PLGA but can extensively swell PDMS. The gelatin-based mold was replicated by initially molding a gelatin solution onto a silicon master with a subsequent sol-gel transition by temperature reduction. The patterned gel played the same role as the regular PDMS mold in the micromolding process, capable of creating one PLGA particle per well. A PLGA methylene chloride-drug solution was spread onto the gelatin-based mold, allowing the pre-particle solution to fill each well before solvent evaporation. Taking advantage of reversible sol-gel conversion, the drug-loaded PLGA particles could be easily separated from the gel mold. Cargo release study indicated that the PLGA particles were able to be biodegraded after the entire micromolding process.

An enzyme-triggered, cleavable peptide linkage was incorporated into particles fabricated by micromolding from a quartz template [105]. A solution of diacrylated peptide with a sequence of Gly-Phe-Leu-Gly-Lys (diacrylated GFLGK) was mixed with an inert crosslinker (PEG diacrylate), cast onto a sacrificial layer (PVA), and molded by the quartz template. The particles were solidified under exposure to UV irradiation. It is worth noting that there was an excess layer connecting all of the particles. Oxygen plasma etching was necessary to remove this residual layer, resulting in isolated particles. The uniform particle size was $50 \mathrm{~nm}$ with well-controlled shape. The tetra-peptide sequence of GFLG in diacrylated GFLGK was sensitive to lysosomal thiol proteases, particularly Cathepsin B (a cysteine protease). Cathepsin B levels in tumor cells and tissues of patients with lung cancer are significantly elevated and the GFLG-containing particle could conceivably be used as an anticancer treatment. Consequently, the particles composed of equimolar diacrylated GFLGK and PEG diacrylate began to degrade within 30 min and fully degraded between 24 $\mathrm{h}$ and $48 \mathrm{~h}$, in the presence of $25 \mathrm{U} / \mathrm{mL}$ Cathepsin B in pH 5 PBS (Fig. 8). Bioactive antibodies and nucleic acids were encapsulated within the particles, and the cargo was released by this enzymatic trigger.

\section{Conclusion and Future Prospects}

An increasing number of stimuli-responsive materials are expected to be used in top-down particle engineering methods. The combination of stimuli-responsive materials and topdown fabrication methods allow for active tailoring of drug delivery to specific sites of interest. Research regarding stimuli-responsive materials and top-down particle fabrication methods is still in early developmental stages and much work will need to be conducted for achieving clinical application. The major physiological stimuli that can trigger drug release and particle degradation, including $\mathrm{pH}$ gradient, redox gradient, and enzymatic response, can reduce side effects and enhance the effectiveness of certain medicines. Drug loading and release profiles have been well characterized in certain stimuli-responsive microgel particles and biodegradable polymeric particles, and thus, these systems will be considered as major candidates for engineering of drug vehicles. All in all, stimuli-responsive engineering nanomedicines can shift the paradigm in the delivery of medicine and diagnostics. 


\section{Acknowledgments}

Funding is gratefully acknowledged from National Institutes of Health Grants 1R01EB009565-02 and NIHR01, U54CA1 19373 (Carolina Center of Cancer Nanotechnology), and 1DP10D006432-01 (NIH Pioneer Award); the University Cancer Research Fund at the University of North Carolina at Chapel Hill; the William R. Kenan Professorship at the University of North Carolina at Chapel Hill; and a sponsored research agreement with Liquidia Technologies.

\section{References}

1. Petros RA, DeSimone JM. Strategies in the design of nanoparticles for therapeutic application. Nature Rev. 2010; 9:615-627.

2. Li S-D, Huang L. Pharmacokinetics and biodistribution of nanoparticles. Mol. Pharmaceutics. 2008; 5:496-504.

3. del Valle EMM, Galan MA, Carbonell RG. Drug delivery technologies: the way forward in the new decade. Ind. Eng. Chem. Res. 2009; 48:2475-2486.

4. Barenholz Y. Liposome application: problems and prospects. Curr. Opin. Colloid Interface Sci. 2001; 6:66-77.

5. Torchilin VP. Targeted polymeric micelles for delivery of poorly soluble drugs. Cell. Mol. Life Sci. 2004; 61:2549-2559. [PubMed: 15526161]

6. Kwon GS, Kataoka K. Block-Copolymer Micelles as Long-Circulating Drug Vehicles. Adv. Drug Deliv. Rev. 1995; 16:295-309.

7. Bae Y, Kataoka K. Intelligent polymeric micelles from functional poly(ethylene glycol)-poly(amino acid) block copolymers. Adv. Drug. Deliv. Rev. 2009; 61:768-784. [PubMed: 19422866]

8. Wang YP, Xu HP, Zhang X. Tuning the amphiphilicity of building blocks: controlled self-assembly and disassembly for functional supramolecular materials. Adv. Mater. 2009; 21:2849-2864.

9. Merkel TJ, Herlihy KP, Nunes J, Orgel RM, Rolland JP, DeSimone JM. Scalable, shape-specific, top-down fabrication methods for the synthesis of engineered colloidal particles. Langmuir. 2010; 26:13086-13096. [PubMed: 20000620]

10. del Campo A, Arzt E. Fabrication approaches for generating complex micro- and nanopatterns on polymeric surfaces. Chem. Rev. 2008; 108:911-945. [PubMed: 18298098]

11. Farokhzad OC, Langer R. Impact of nanotechnology on drug delivery. ACS Nano. 2009; 3:16-20. [PubMed: 19206243]

12. Mitragotri S, Lahann J. Physical approaches to biomaterial design. Nat. Mater. 2009; 8:15-23. [PubMed: 19096389]

13. Gref R, Minamitake Y, Peracchia MT, Trubetskoy V, Torchilin V, Langer R. Biodegradable longcirculating polymeric nanospheres. Science. 1994; 263:1600-1603. [PubMed: 8128245]

14. Howard MD, Jay M, Dziublal TD, Lu XL. PEGylation of nanocarrier drug delivery systems: state of the art. J. Biomed. Nanotechnol. 2008; 4:133-148.

15. Gabizon A, Shmeeda H, Horowitz AT, Zalipsky S. Tumor cell targeting of liposome-entrapped drugs with phospholipid-anchored folic acid-PEG conjugates. Adv. Drug. Deliv. Rev. 2004; 56:1177-1192. [PubMed: 15094214]

16. Choi CH, Alabi CA, Webster P, Davis ME. Mechanism of active targeting in solid tumors with transferrin-containing gold nanoparticles. Proc. Natl. Acad. Sci. USA. 2010; 107:1235-1240. [PubMed: 20080552]

17. Wang MD, Shin DM, Simons JW, Nie S. Nanotechnology for targeted cancer therapy. Expert Rev. Anticancer Ther. 2007; 7:833-837. [PubMed: 17555393]

18. Brannon-Peppas L, Blanchette JO. Nanoparticle and targeted systems for cancer therapy. Adv. Drug. Deliv. Rev. 2004; 56:1649-1659. [PubMed: 15350294]

19. Lu Y, Low PS. Immunotherapy of folate receptor-expressing tumors: review of recent advances and future prospects. Journal of Controlled Release. 2003; 91:18-29.

20. Vinogradov SV, Bronich TK, Kabanov AV. Nanosized cationic hydrogels for drug delivery: preparation, properties and interactions with cells. Adv. Drug. Deliv. Rev. 2002; 54:135-147. [PubMed: 11755709] 
21. Choi HS, Liu W, Misra P, Tanaka E, Zimmer JP, Ipe BI, Bawendi MG, Frangioni JV. Renal clearance of quantum dots. Nat. Biotech. 2007; 25:1165-1170.

22. Llium L, Davis SS, Wilson CG, Thomas NW, Frier M, Hardy JG. Blood clearance and organ deposition of intravenously administered colloidal particles. The effects of particle size, nature and shape. Int. J. Pharm. 1982; 12:135-146.

23. Alexis F, Pridgen E, Molnar LK, Farokhzad OC. Factors affecting the clearance and biodistribution of polymeric nanoparticles. Mol. Pharmacol. 2008; 5:505-515.

24. Kohane DS. Microparticles and nanoparticles for drug delivery. Biotechnol. Bioeng. 2007; 96:203-209. [PubMed: 17191251]

25. Gratton SEA, Ropp PA, Pohlhaus PD, Luft JC, Madden VJ, Napier ME, DeSimone JM. The effect of particle design on cellular internalization pathways. Proc. Natl Acad. Sci. USA. 2008; 105:11613-11618. [PubMed: 18697944]

26. Geng Y, Dalhaimer P, Cai S, Tsai R, Tewari M, Minko T, Discher DE. Shape effects of filaments versus spherical particles in flow and drug delivery. Nature Nanotech. 2007; 2:249-255.

27. Champion JA, Mitragotri S. Role of target geometry in phagocytosis. Proc. Natl Acad. Sci. USA. 2006; 103:4930-4934. [PubMed: 16549762]

28. Merkel TJ, Jones SW, Herlihy KP, Kersey FR, Shields AR, Napier ME, Luft JC, Wu H, Zamboni WC, Wang AZ, Bear JE, DeSimone JM. Using mechanobiological mimicry of red blood cells to extend circulation times of hydrogel microparticles. Proc. Natl Acad. Sci. USA. 2011; 108:586591. [PubMed: 21220299]

29. Kost J, Langer R. Responsive polymeric delivery systems. Adv. Drug Deliv. Rev. 1991; 6:19-50.

30. Gillies ER, Frechet JMJ. Development of acid-sensitive copolymer micelles for drug delivery. Pure Appl. Chem. 2004; 76:1295-1307.

31. Saito G, Swanson JA, Lee K-D. Drug delivery strategy utilizing conjugation via reversible disulfide linkages: role and site of cellular reducing activities. Adv. Drug Deliv. Rev. 2003; 55:199-215. [PubMed: 12564977]

32. Miyata T, Uragami T, Nakamae K. Biomolecule-sensitive hydrogels. Adv. Drug. Deliv. Rev. 2002; 54:79-98. [PubMed: 11755707]

33. Dissemond J, Witthoff M, Brauns TC, Harberer D, Gros M. pH values on chronic wounds: evaluation during modern wound therapy. Hautarzt. 2001; 54:959-965. [PubMed: 14513243]

34. Schmaljohann D. Thermo- and $\mathrm{pH}-$ responsive polymers in drug delivery. Adv. Drug Deliv. Rev. 2006; 58:1655-1670. [PubMed: 17125884]

35. Mellman I, Fuchs R, Helenius A. Acidification of the endocytic and exocytic pathways. Annu. Rev. Biochem. 1986; 55:663-700. [PubMed: 2874766]

36. Di Stefano G, Lanza M, Kratz F, Merna L, Fiume L. A novel method for coupling doxorubicin to lactosaminated human albumin by an acid sensitive hydrazone bond: synthesis, characterization and preliminary biological properties of the conjugate. Eur. J. Pharm. Sci. 2004; 23:393-397. [PubMed: 15567293]

37. Patel VF, Hardin JN, Mastro JM, Law KL, Zimmermann JL, Ehlhardt WJ, Woodland JM, Starling JJ. Novel acid labile COL1 trityl-linked difluoronucleoside immunoconjugates: synthesis, characterization, and biological activity. Bioconjugate Chem. 1996; 7:497-510.

38. Shen WC, Ryser HJP. cis-Aconityl spacer between daunomycin and macromolecular carriers: a model of $\mathrm{pH}$-sensitive linkage releasing drug from a lysosomotropic conjugate. Biochem. Biophys. Res. Commun. 1981; 102:1048-1054. [PubMed: 7306187]

39. Shin J, Shum P, Thompson DH. Acid-triggered release via dePEGylation of DOPE liposomes containing acid-labile vinyl ether PEG-lipids. J. Controlled Release. 2003; 91:187-200.

40. Heffernan MJ, Murthy N. Polyketal nanoparticles: a new pH-sensitive biodegradable drug delivery vehicle. Bioconjugate Chem. 2005; 16:1340-1342.

41. Gillies ER, Frechet JMJ. pH-responsive copolymer assemblies for controlled release of doxorubicin. Bioconjugate Chem. 2005; 16:361-368.

42. Toncheva V, Schacht E, Ng SY, Barr J, Heller J. Use of block copolymers of poly(ortho esters) and poly(ethylene glycol) micellar carriers as potential tumour targeting systems. J. Drug Targetting. 2003; 11:345-353. 
43. Oishi M, Nagasaki Y, Itaka K, Nishiyama N, Kataoka K. Lactosylated poly(ethylene glycol)siRNA conjugate through acid-labile beta.-thiopropionate Linkage to construct $\mathrm{pH}$-sensitive polyion complex micelles achieving enhanced gene silencing in hepatoma cells. J. Am. Chem. Soc. 2005; 127:1624-1625. [PubMed: 15700981]

44. Parrott MC, Luft JC, Byrne JD, Fain JH, Napier ME, DeSimone JM. Tunable bifunctional silyl ether cross-linkers for the design of acid-sensitive biomaterials. J. Am. Chem. Soc. 2010; 132:17928-17932. [PubMed: 21105720]

45. Gilbert HF. Thiol / disulfide exchange equilibria and disulfide bond stability. Exp. Neurol. 1995; 132:54-61. [PubMed: 7720826]

46. Meister A. Glutathione deficiency produced by inhibition of its synthesis, and its reversal: applications in research and therapy. Pharmacol. Ther. 1991; 51:155-194. [PubMed: 1784629]

47. Gainey D, Short S, McCoy KL. Intracellular location of cysteine transport activity correlates with productive processing of antigen disulfide. J. Cell. Physiol. 1996; 168:248-254. [PubMed: 8707860]

48. Ishihara K, Matsui K. Glucose-responsive insulin release from polymer capsule. J. Polym. Sci. Polym. Lett. Ed. 1986; 24:413-417.

49. Hassan CM, Doyle III FJ, Peppas NA. Dynamic behavior of glucose-responsive poly(methacrylic acid-g-ethylene glycol) hydrogels. Mcaromolecules. 1997; 30:6166-6173.

50. Makino K, Mack EJ, Okano T, Kim SW. A microcapsule self-regulating delivery system for insulin. J. Controlled Release. 1990; 12:235-239.

51. Hovgaard L, Brondsted H. Dextran hydrogels for colon-specific drug delivery. J. Controlled Release. 1995; 36:159-166.

52. Barrett, AJ.; Rawlings, ND.; Woessner, JF. The handbook of proteolytic enzymes. 2nd ed.. Academic Press; 2003. ISBN 0-12-079610-4

53. Hedstrom L. Serine protease mechanism and specificity. Chem. Rev. 2002; 102:4501-4524. [PubMed: 12475199]

54. Tabák AG, Jokela M, Akbaraly TN, Brunner EJ, Kivimäki M, Witte DR. Trajectories of glycaemia, insulin sensitivity, and insulin secretion before diagnosis of type 2 diabetes: an analysis from the Whitehall II study. Lancet. 2009; 373:2215-2221. [PubMed: 19515410]

55. Thorsen T, Roberts RW, Arnold FH, Quake SR. Dynamic pattern formation in a vesicle-generating microfluidic device. Phys. Rev. Lett. 2001; 86:4163-4166. [PubMed: 11328121]

56. Garstecki P, Fuerstman MJ, Stone HA, Whitesides GM. Formation of droplets and bubbles in a microfluidic T-junction - scaling and mechanism of break-up. Lab Chip. 2006; 6:437-446. [PubMed: 16511628]

57. Anna SL, Bontoux N, Stone HA. Formation of dispersions using "flow focusing" in microchannels. Appl. Phys. Lett. 2003; 82:364-366.

58. Christopher GF, Anna SL. Microfluidic methods for generating continuous droplet streams. J. Phys. D: Appl. Phys. 2007; 40:R319-R336.

59. Hung L-H, Lee AP. Mircrofluidic devices for the synthesis of nanoparticles and biomaterials. J. Med. Biol. Eng. 2007; 27:1-6.

60. Dendukuri D, Doyle PS. The synthesis and assembly of polymeric microparticles using microfluidics. Adv. Mater. 2009; 21:4071-4086.

61. Shum HC, Abate AR, Lee D, Studart AR, Wang B, Chen C-H, Thiele J, Shah RK, Krummel A, Weitz DA. Droplet microfluidics for fabrication of non-spherical particles. Macromol. Rapid Commun. 2010; 31:108-118. [PubMed: 21590882]

62. Xu S, Nie Z, Seo M, Lewis P, Kumacheva E, Stone HA, Garstecki P, Weibel DB, Gitlin I, Whitesides GM. Generation of monodisperse particles by using microfluidics: control over size, shape, and composition. Angew. Chem. Int. Ed. 2005; 44:724-728.

63. Dendukuri D, Pregibon DC, Collins J, A. Hatton T, Doyle PS. Continuous-flow lithography for high-throughput microparticle synthesis. Nat. Mater. 2006; 5:365-369. [PubMed: 16604080]

64. Jang JH, Dendukuri D, Hatton TA, Thomas EL, Doyle PS. A route to three-dimensional structures in a microfluidic device: stop-flow interference lithography. Angew. Chem. Int. Ed. 2007; 46:9027-9031. 
65. Slaughter BV, Khurshid SS, Fisher OZ, Khademhosseini A, Peppas NA. Hydrogels in regenerative medicine. Adv. Mater. 2009; 21:3307-3329. [PubMed: 20882499]

66. Kabanov AV, Vinogradov SV. Nanogels as pharmaceutical carriers: finite networks of infinite capabilities. Angew. Chem. Int. Ed. 2009; 48:5418-5429.

67. Kumar N, Ravikumar MNV, Domb AJ. Biodegradable block copolymers. Adv. Drug Deliv. Rev. 2001; 53:23-44. [PubMed: 11733116]

68. Mundargi RC, Babu VR, Rangaswamy V, Patel P, Aminabhavi TM. Nano/micro technologies for delivering macromolecular therapeutics using poly(D,L-lactide-co-glycolide) and its derivatives. J. Controlled Release. 2008; 125:193-209.

69. Lu L, Peter SJ, Lyman MD, Lai HL, Leite SM, Tamada JA, Uyama S, Vacanti JP, Langer R, Mikos AG. In vitro and in vivo degradation of porous poly(DL-lactic-co-glycolic acid) foams. Biomaterials. 2000; 21:1837-1845. [PubMed: 10919687]

70. Astete CE, Sabliov CM. Synthesis and characterization of PLGA nanoparticles. J. Biomater. Sci., Polym. Ed. 2006; 17:247-289. [PubMed: 16689015]

71. Xu Q, Hashimoto M, Dang TT, Hoare T, Kohane DS, Whitesides GM, Langer R, Anderson DG. Preparation of monodisperse biodegradable polymer microparticles using a microfluidic flowfocusing device for controlled drug delivery. Small. 2009; 5:1575-1581. [PubMed: 19296563]

72. Karnik R, Gu F, Basto P, Cannizzaro C, Dean L, Kyei-Manu W, Langer R, Farokhzad OC. Microfluidic platform for controlled synthesis of polymeric nanoparticles. Nano Lett. 2008; 8:2906-2912. [PubMed: 18656990]

73. Shum HC, Kim J-W, Weitz DA. Microfluidic fabrication of monodisperse biocompatible and biodegradable polymersomes with controlled permeability. J. Am. Chem. Soc. 2008; 130:95439549. [PubMed: 18576631]

74. Workman VL, Dunnett SB, Kille P, Palmer DD. Microfluidic chip-based synthesis of alginate microspheres for encapsulation of immortalized human cells. Biomicrofluidics. 2007; 1:014105.

75. Johann RM, Renaud P. Microfluidic patterning of alginate hydrogels. Biointerphases. 2007; 2:7379. [PubMed: 20408639]

76. Luo D, Pullela SR, Marquez M, Cheng Z. Cell encapsules with tuanble transport and mechanical properties. Biomicrofluidics. 2007; 1:034102.

77. Shah RK, Kim J-W, Agresti JJ, Weitz DA, Chu J-Y. Fabricaiton of monodisperse thermosensitive microgels and gel capsules in microfluidic devices. Soft Matt. 2008; 4:2303-2309.

78. Dendukuri D, Tsoi K, Hatton TA, Doyle PS. Controlled synthesis of nonspherical microparticles using microfluidics. Langmuir. 2005; 21:2113-2118. [PubMed: 15751995]

79. De Geest BG, Urbanski JP, Thorsen T, Demeester J, De Smedt SC. Synthesis of monodisperse biodegradable microgels in microfluidic devices. Langmuir. 2005; 21:10275-10279. [PubMed: 16262275]

80. Hwang DK, Oakey J, Toner M, Arthur JA, Anseth KS, Lee S, Zeiger A, Vliet KJV, Doyle PS. Stop-flow lithography for the production of shape-evolving degradable microgel particles. J. Am. Chem. Soc. 2009; 131:4499-4504. [PubMed: 19215127]

81. Shi J, Votruba AR, Farokhzad OC, Langer R. Nanotechnology in drug delivery and tissue engineering: from discovery to applications. Nano Lett. 2010; 10:3223-3230. [PubMed: 20726522]

82. Khademhosseini A, Langer R. Microengineered hydrogels for tissue engineering. Biomaterials. 2007; 28:5087-5092. [PubMed: 17707502]

83. Helgeson ME, Chapin SC, Doyle PS. Hydrogel microparticles from lithographic processes: novel materials for fundamental and applied colloid science. Curr. Opin. Colloid Interface Sci. 2011; 16:106-117. [PubMed: 21516212]

84. Badaire S, Cottin-Bizonne C, Woody JW, Yang A, Stroock AD. Shape selectivity in the assembly of lithographically designed colloidal particles. J. Am. Chem. Soc. 2007; 129:40-41. [PubMed: 17199278]

85. Liu VA, Bhatia SN. Three-dimensional photopatterning of hydrogels containing living cells. Biomed. Microdevices. 2002; 4(4):257-266.

86. Hernandez CJ, Mason TG. Colloidal alphabet soup: mondisperse dispersions of shape-designed lithoParticles. J. Phys. Chem. C. 2007; 111:4477-4480. 
87. Koh W-G, Revzin A, Pishko MV. Poly(ethylene glycol) hydrogel microstructures encapsulating living cells. Langmuir. 2002; 18:2459-2462. [PubMed: 12088033]

88. Xia Y, Whitesides GM. Soft Lithography. Annu. Rev. Mater. Sci. 1998; 28:153-184.

89. Rolland JP, Maynor BW, Euliss LE, Exner AE, Denison GM, DeSimone JM. Direct fabrication and harvesting of monodisperse, shape-specific nanobiomaterials. J. Am. Chem. Soc. 2005; 127:10096-10100. [PubMed: 16011375]

90. Gratton SEA, Williams SS, Napier ME, Pohlhaus PD, Zhou Z, Wiles KB, Maynor BW, Shen C, Olafsen T, Samulski ET, DeSimone JM. The pursuit of a scalable nanofabrication platform for use in material and life science application. Acc. Chem. Res. 2008; 41:1685-1695. [PubMed: 18720952]

91. Euliss LE, DuPont JA, Gratton S, DeSimone JM. Imparting size, shape, and composition control of materials for nanomedicine. Chem. Soc. Rev. 2006; 35:1095-1104. [PubMed: 17057838]

92. Maynor BW, LaRue I, Hu Z, Rolland JP, Pandya A, Fu Q, Liu J, Spontak RJ, Sheiko SS, Samulski RJ, Samulski ET, DeSimone JM. Supramolecular nanomimetics: replication of micelles, viruses, and other naturally occurring nanoscale objects. Small. 2007; 3:845-849. [PubMed: 17393549]

93. Wang YP, Merkel TJ, Chen K, Fromen CA, Betts DE, DeSimone JM. Generation of a library of particles having controlled sizes and shapes via the mechanical elongation of master templates. Langmuir. 2011; 27:524-528. [PubMed: 21166444]

94. Jeong W, Napier ME, DeSimone JM. Challenging nature's monopoly on the creation of welldefined nanoparticles. Nanomedicine. 2010; 5:633-639. [PubMed: 20528457]

95. Napier ME, DeSimone JM. Nanoparticle drug delivery platform. Poly. Rev. 2007; 47:321-327.

96. Wang J, Tian S, Petros RA, Napier ME, DeSimone JM. The complex role of multivalency in nanoparticles targeting the transferrin receptor for cancer therapies. J. Am. Chem. Soc. 2010; 132:11306-11313. [PubMed: 20698697]

97. Enlow EM, Luft JC, Napier ME, DeSimone JM. Potent engineered PLGA nanoparticles by virtue of exceptionally high chemotherapeutic loadings. Nano Lett. 2011; 11:808-813. [PubMed: 21265552]

98. Petros RA, Ropp PA, DeSimone JM. Reductively labile PRINT particles for the delivery of doxorubicin to HeLa cells. J. Am. Chem. Soc. 2008; 130:5008-5009. [PubMed: 18355010]

99. Kelly JY, DeSimone JM. Shape-specific, monodisperse nano-molding of protein particles. J. Am. Chem. Soc. 2008; 130:5438-5439. [PubMed: 18376832]

100. Fukuda J, Khademhosseini A, Yeo Y, Yang X, Yeh J, Eng G, Blumling J, Wang C-F, Kohane DS, Langer R. Micromolding of photocrosslinkable chitosan hydrogel for spheroid microarray and co-cultures. Biomaterials. 2006; 27:5259-5267. [PubMed: 16814859]

101. Acharya C, Shin CS, McDermott M, Mishra H, Park H, Kwon IC, Park K. The hydrogel template method for fabrication of homogeneous nano/microparticles. J. Controlled Release. 2010; 141:314-319.

102. Yeh J, Ling Y, Karp JM, Gantz J, Chandawarkar A, Eng G, Blumling J III, Langer R, Khademhosseini A. Micromolding of shape-controlled, harvestable cell-laden hydrogels. Biomaterials. 2006; 27:5391-5398. [PubMed: 16828863]

103. Guan J, Ferrell N, Lee LJ, Hansford DJ. Fabrication of polymeric microparticles for drug delivery by soft lithography. Biomaterials. 2006; 27:4034-4041. [PubMed: 16574217]

104. Guan J, He H, Lee LJ, Hansford DJ. Fabrication of particulate reservoir containing, capsulelike, and slef-folding polymer microstructures for drug delivery. Small. 2007; 3:412-418. [PubMed: 17285662]

105. Glangchiai LC, Caldorera-Moore M, Shi L, Roy K. Nanoimprint lithography based fabrication of shape-specific, enzymatically-triggered smart nanoparticles. J. Controlled Release. 2008; 125:263-272. 
A
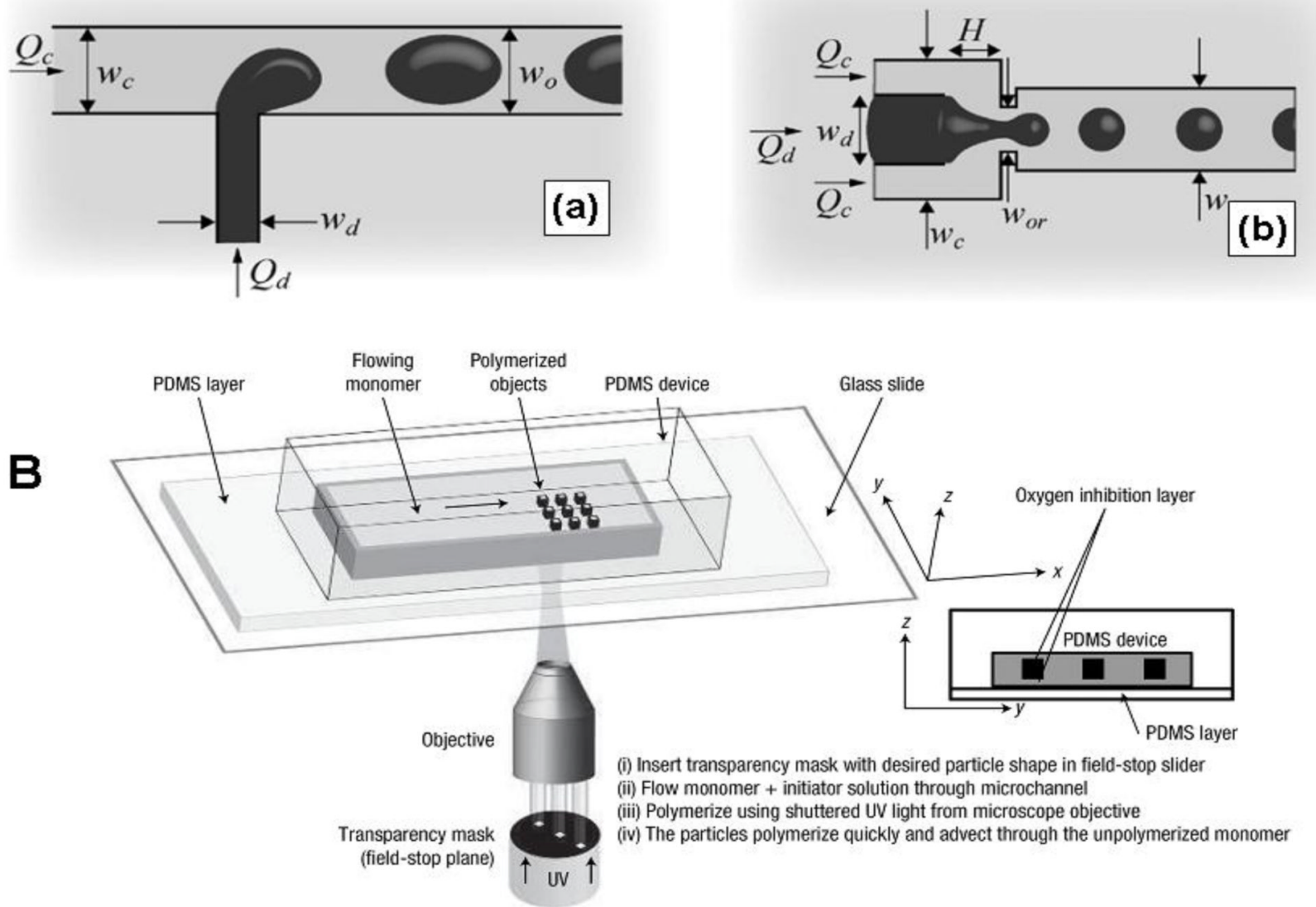

Fig.1.

(A) Microfluidic devices for the fabrication of monodisperse emulsion droplets (a) Tjunction type; (b) Flow focusing Device (FFD). Reproduced from Ref. 58 with permission of Institute of Physics. (B) An experimental setup of Continuous Flow Lithography (CFL). Polymerized particles are generated in the monomer stream flowing through the channel, by a mask-defined UV light beam emanating from the objective. Reproduced from Ref. 63 with permission of Nature Publishing Group. 

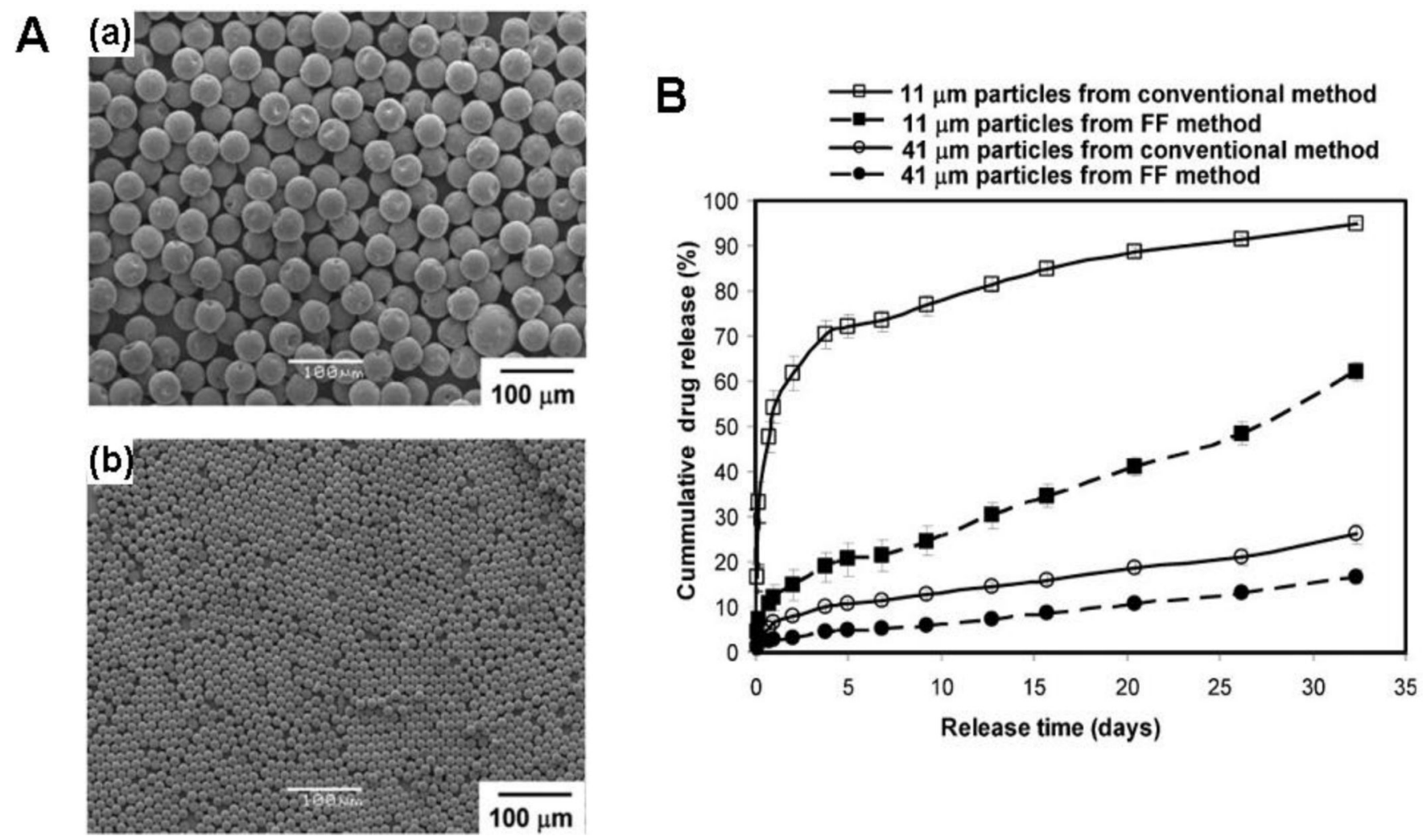

Fig.2.

(A) Microparticles prepared via microfluidics with average size of: (a) $41 \mu \mathrm{m}$, (b) $11 \mu \mathrm{m}$.

(B) The comparison of drug-release profiles from monodisperse microparticles prepared with microfluidic devices and polydisperse microparticles prepared using the conventional single emulsion technique. Reproduced from Ref. 71 with permission of John Wiley \& Sons, Inc. 


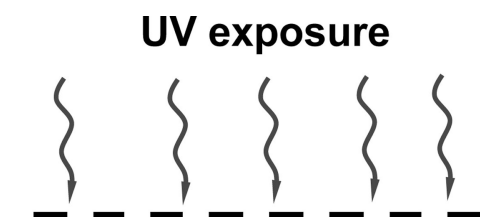

UV exposure
Prepolymer

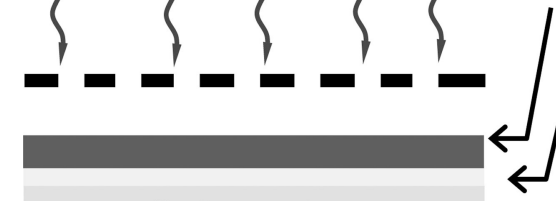

Substrate

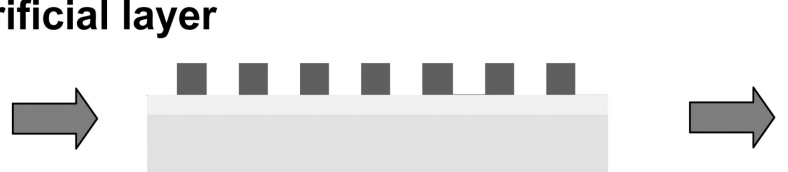

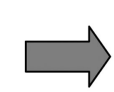

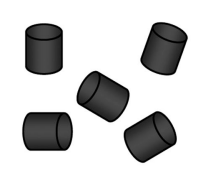

Free particles

Fig.3.

Schematic illustration of the photolithography method to engineer shape and size specific particles. 

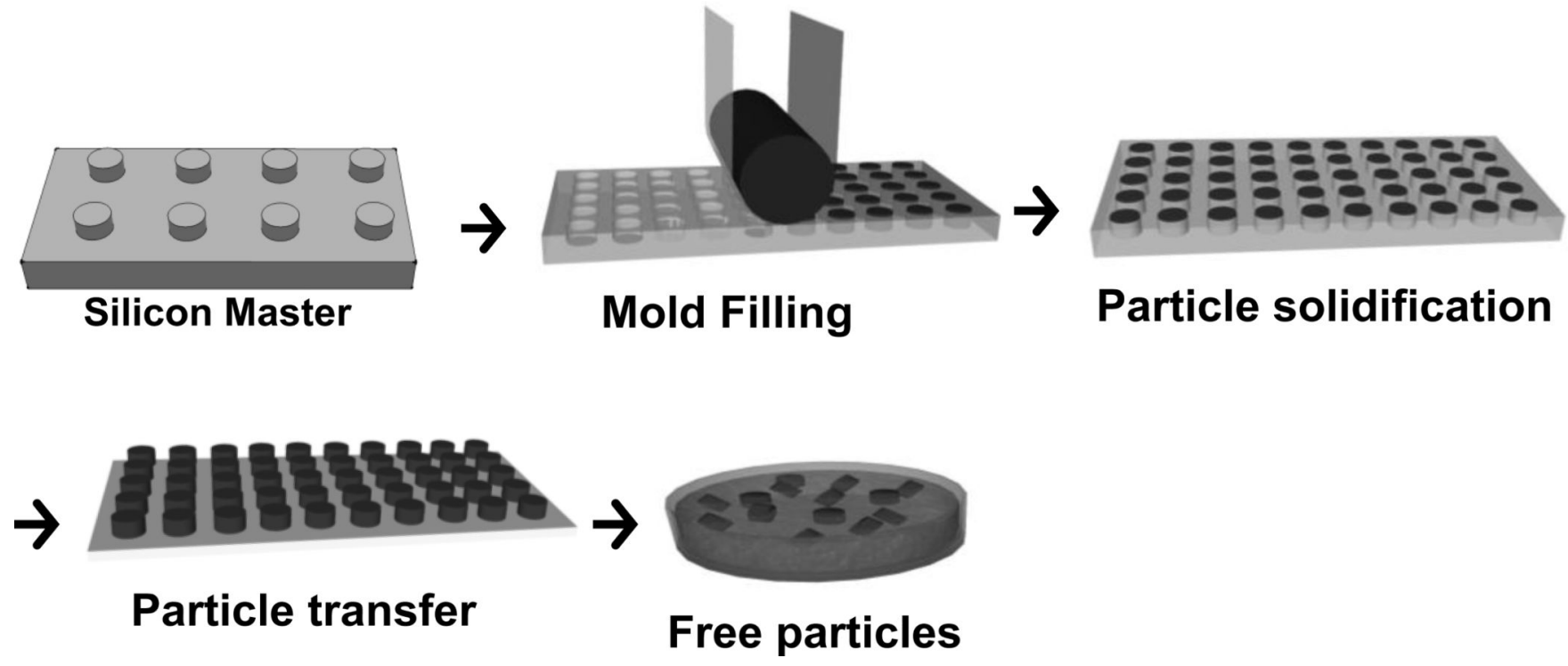

Fig. 4.

General schematic representation of Particle Replication In Non-wetting Templates (PRINT). 

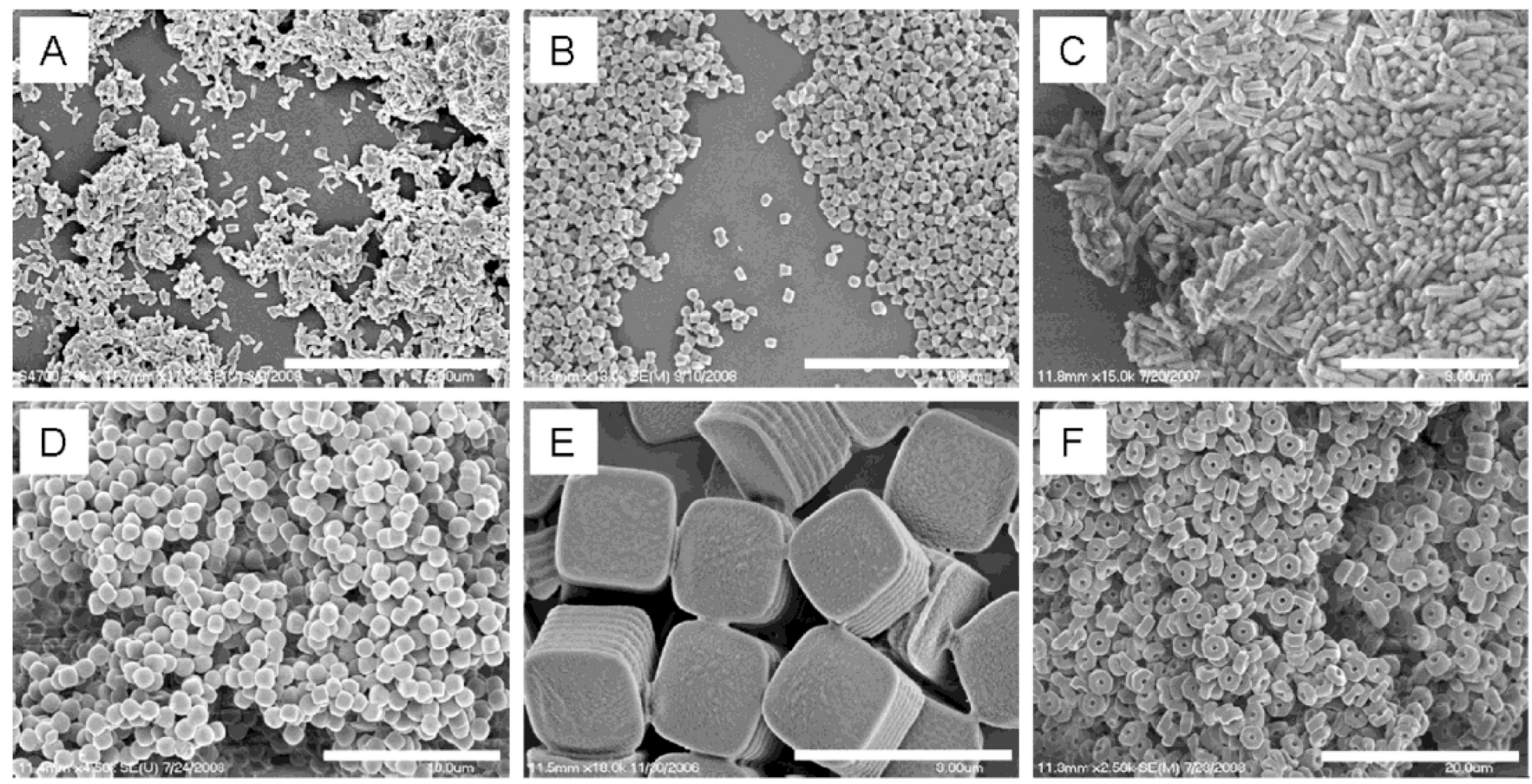

Fig. 5.

PRINT PLGA nano- and microparticles. (A) $80 \mathrm{~nm} \times 320 \mathrm{~nm}$ cylinders, (B) $200 \mathrm{~nm} \times 200$ nm cylinders, (C) $200 \mathrm{~nm} \times 600 \mathrm{~nm}$ cylinders, (D) $1 \mu \mathrm{m}$ sphere approximates, (E) $2 \mu \mathrm{m}$ cubes with ridges, and (F) $3 \mu \mathrm{m}$ particles with center fenestrations. Scale bars: (A) $5 \mu \mathrm{m}$, (B) $4 \mu \mathrm{m}$, (C) $3 \mu \mathrm{m}$, (D) $10 \mu \mathrm{m}$, (E) $3 \mu \mathrm{m}$, and (F) $20 \mu \mathrm{m}$. Reproduced from Ref. 97 with permission of American Chemical Society. 
<smiles>C=CC(=O)OCC(CO)(COC(=O)C=C)COC(=O)C=C</smiles>

Trimethylolpropane ethoxylate (14/3 EO/OH) triacrylate (Inert crosslinker)<smiles>C=C(C)C(=O)OCC[NH3+]</smiles>

2-aminoethylmethacrylate (Postive charge creator)<smiles>C=CC(=O)NCCSSCCNC(=O)C=C</smiles>

$\mathrm{N}, \mathrm{N}^{\prime}$-cystaminebisacrylamide (Reductively labile crosslinker)<smiles>O=C(c1ccccc1)C1(O)CCCCC1</smiles>

1-hydroxycyclohexyl phenyl ketone (Photo initiator)

Fig. 6.

Building blocks for the reductively labile PRINT particles. 
$\mathbf{A}$<smiles>[R][Sb]([R])(Cl)Cl</smiles><smiles>[R][Sb]([R])(OCCOC(=O)C=C)OCCOC(=O)C=C</smiles>

$1 \mathrm{R}=\mathrm{Me}$ (DMS)

$2 \mathrm{R}=\mathrm{Et}(\mathrm{DES})$

$3 \mathrm{R}=\mathrm{iPr}(\mathrm{DIS})$<smiles>C=CC(=O)OCCO[C@@H](C)C(C)(C)[Si](OCCOC(=O)C=C)(OCCOC(=O)C=C)C(C)(C)[13CH3]</smiles>

B

a

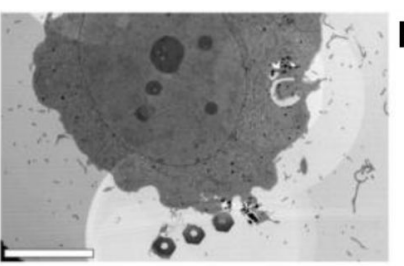

e

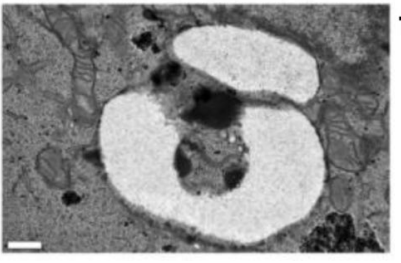

b
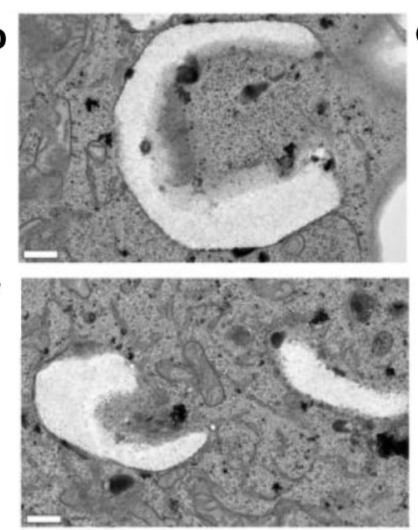
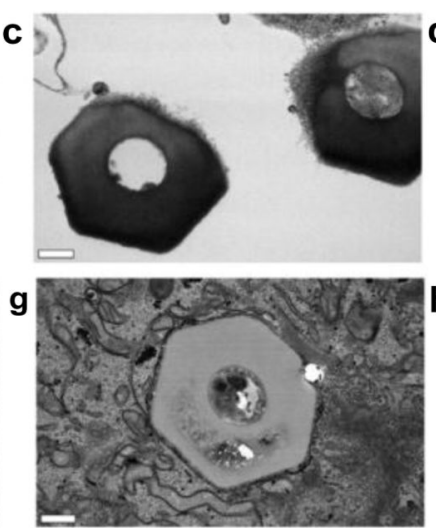
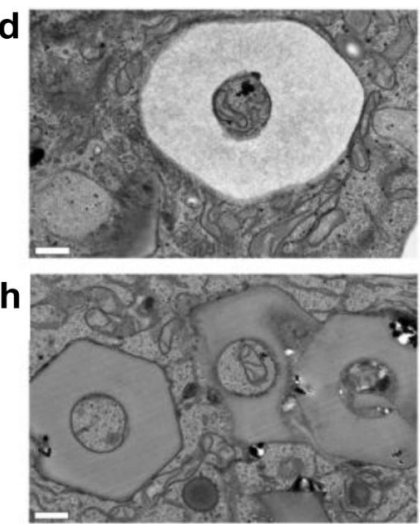

Fig. 7.

(A) Synthesis of photo-curable silyl ether cross-linkers. (B) TEM micrographs of PRINT hexnut particles incubated in HeLa cells: (a-f) rapidly degrading hexnut particles fabricated from the DMS cross-linker [scale bars: (a) $10 \mu \mathrm{m}$; (b-f) $0.5 \mu \mathrm{m}$; (g, h) nondegrading hexnut particles fabricated from the DTS cross-linker (scale bars: $0.5 \mu \mathrm{m}$ ). Reproduced from Ref. 44 with permission of American Chemical Society. 

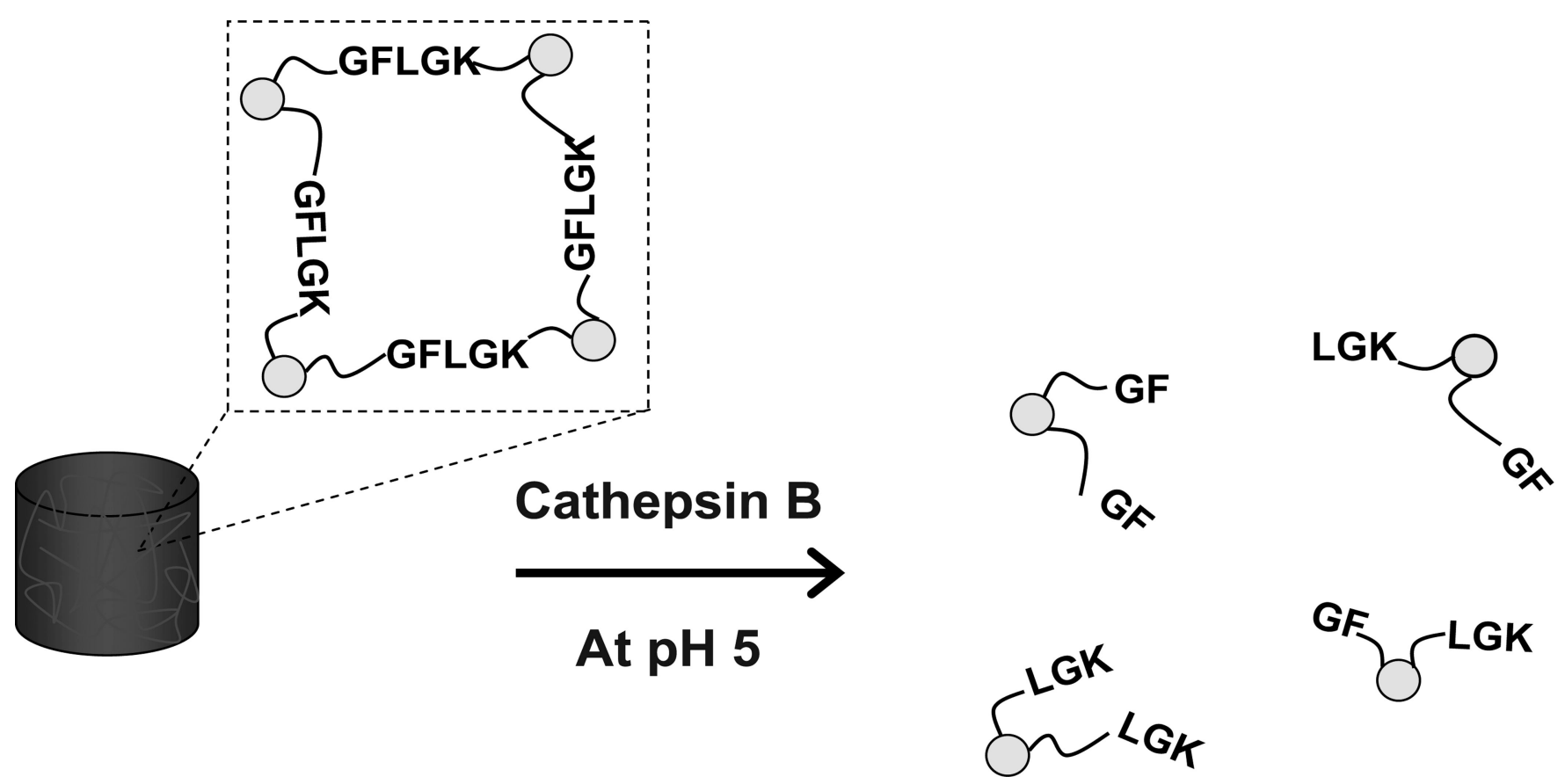

Fig.8.

The enzymatically-triggered biodegradation of micromolding GFLGK particles. 
Table 1

List of top-down strategies for the creation of engineered biodegradable particles in certain drug delivery application.

\begin{tabular}{|c|c|c|c|c|}
\hline $\begin{array}{l}\text { Particle } \\
\text { fabrication } \\
\text { tools }\end{array}$ & Size range & Shape range & $\begin{array}{l}\text { Biodegradable particle } \\
\text { matrices. }\end{array}$ & Cargo \\
\hline $\begin{array}{l}\text { Microfluidic } \\
\text { Particle } \\
\text { Fabrication }\end{array}$ & $3 \mu \mathrm{m}-200 \mu \mathrm{m}$ & $\begin{array}{l}\text { Spheres, ellipsoids, } \\
\text { cylinders, discs } \\
\text { (T-junction or FFD) } \\
\text { Non-spherical, } \\
\text { defined by } \\
\text { photomask (CFL or } \\
\text { SFL) }\end{array}$ & $\begin{array}{l}\text { Biodegradable polymers } \\
\text { (PLGA, PEG-PLGA) Ref. } \\
\text { 71-73; gelator. Ref. 74-78; } \\
\text { acrylated PEG Ref. } 79,80\end{array}$ & $\begin{array}{l}\text { Doxorubicin, } \\
\text { DNA, quantum } \\
\text { dots, proteins }\end{array}$ \\
\hline Photolithography & $\begin{array}{l}\geq 100 \mathrm{~nm} \text { in } \\
\text { thickness; } \geq 800 \\
\text { nm in lateral } \\
\text { dimension }\end{array}$ & 2D, non-spherical & $\begin{array}{l}\text { Photocurable prepolymers } \\
\text { only. Ref. } 85-87\end{array}$ & $\begin{array}{l}\text { Living cells, } \\
\text { proteins }\end{array}$ \\
\hline $\begin{array}{l}\text { PRINT and other } \\
\text { micromolding } \\
\text { methods }\end{array}$ & $10 \mathrm{~nm}-200 \mu \mathrm{m}$ & $\begin{array}{l}\text { Worm, cylinder, etc. } \\
\text { More complicated } \\
\text { structure combining } \\
\text { mechanical } \\
\text { stretching }\end{array}$ & $\begin{array}{l}\text { Biodegradable polymers, } \\
\text { Ref. } 97,103,104 ; \mathrm{pH} \\
\text { sensitive, Ref. } 44 ; \\
\text { reductively labile } \\
\text { acrylates, Ref. } 98 ; \\
\text { proteins, Ref. } 99,105 .\end{array}$ & $\begin{array}{l}\text { Imaging agents, } \\
\text { isRNA, DNA, } \\
\text { anti-cancer drugs, } \\
\text { proteins, } \\
\text { antibodies }\end{array}$ \\
\hline
\end{tabular}

